根ザ方 》生易万學 附资几 法方

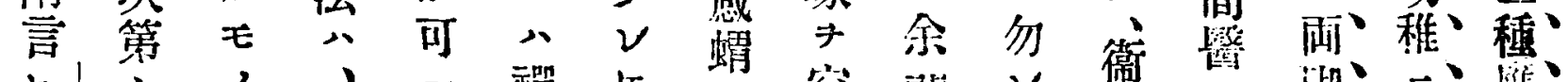

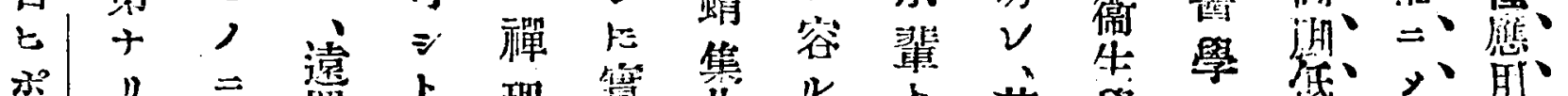

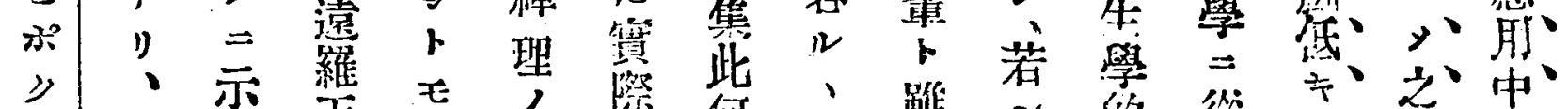

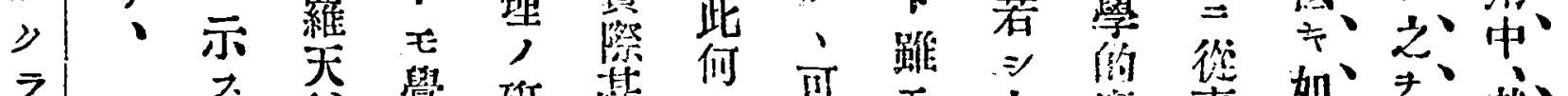

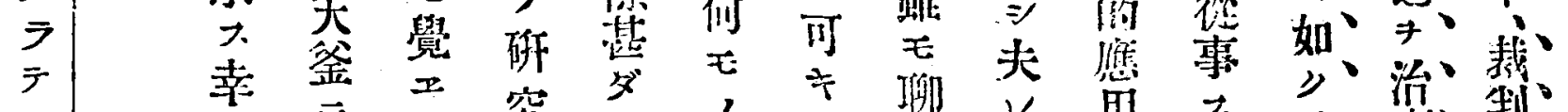

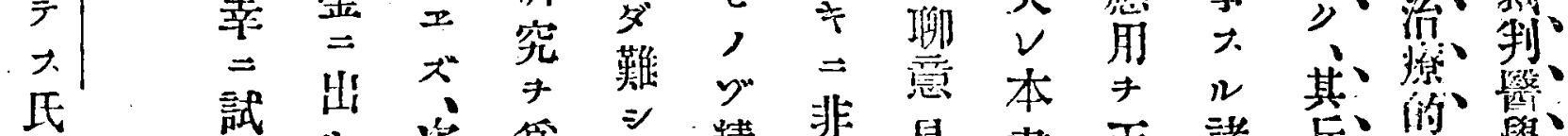



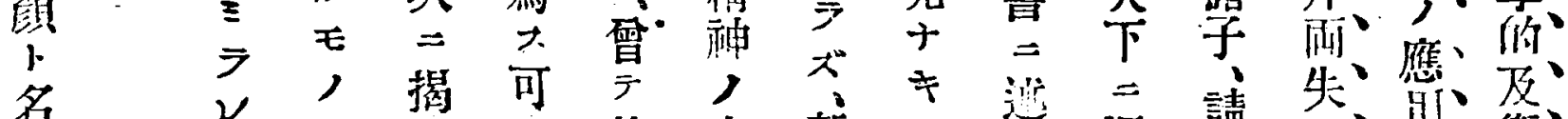

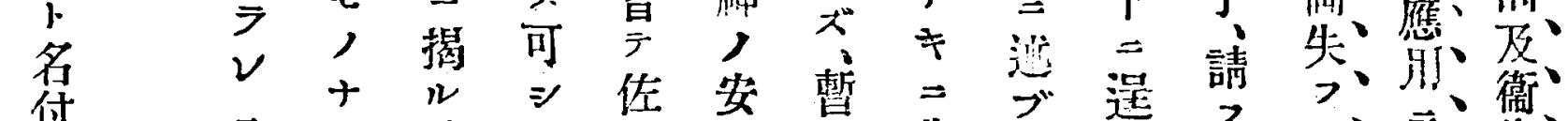

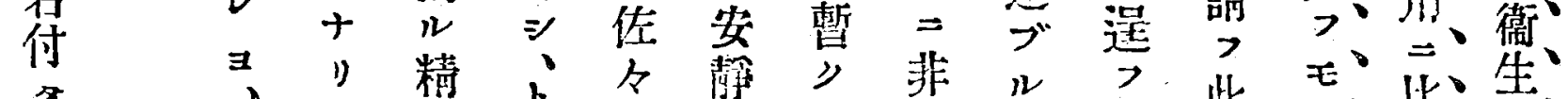
偉

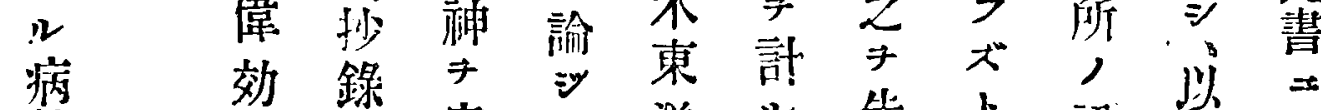

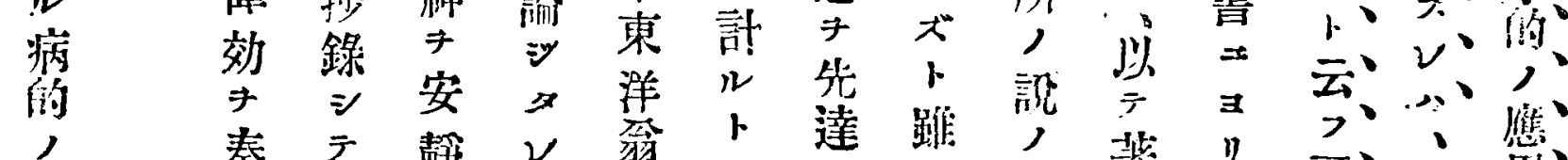
顏 奏 テ 䈹 2 出

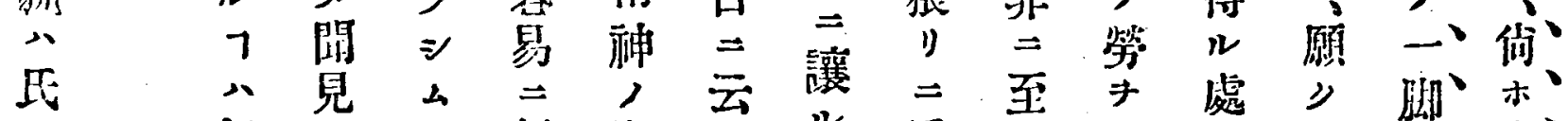

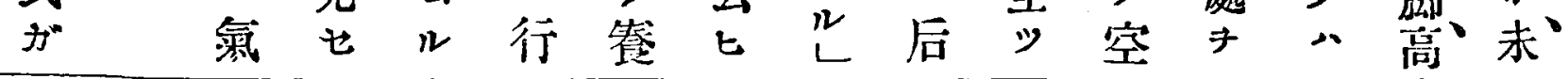

$\bigcirc$ 慮 犆 闰 $P$ 奏此化誘式分回第

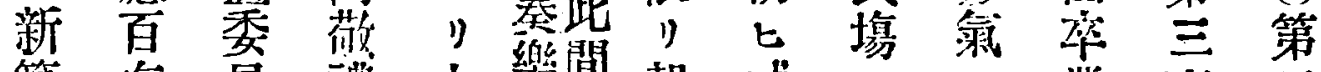

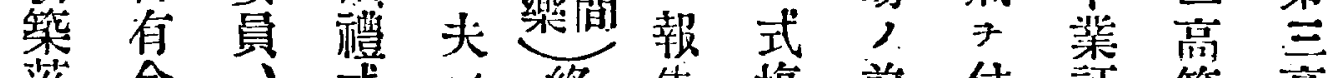
落余市式 $\nu$ 終告韵前付詿等高

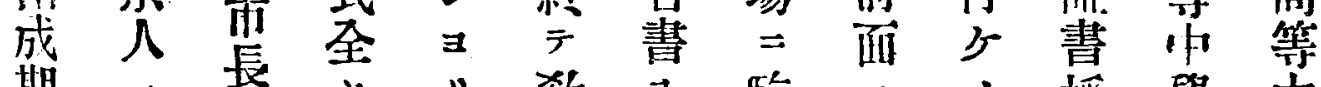
期 $=$ 長 $》$ 》敎



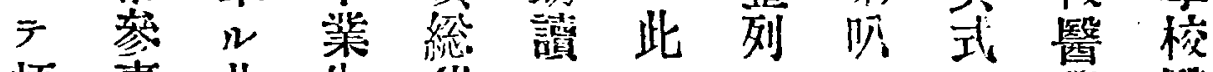

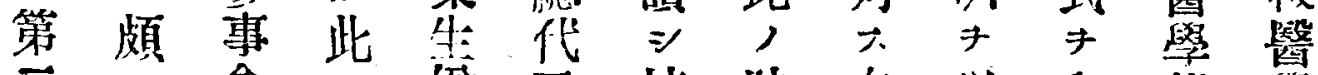

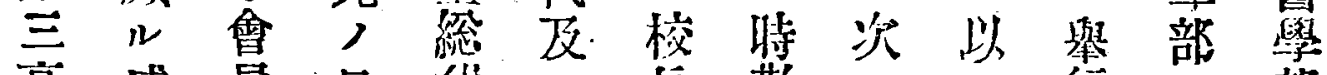
高盛員日代七誩歌 $\Rightarrow$ 行 $\Rightarrow$ 部

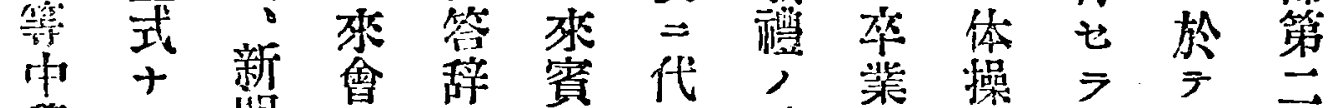

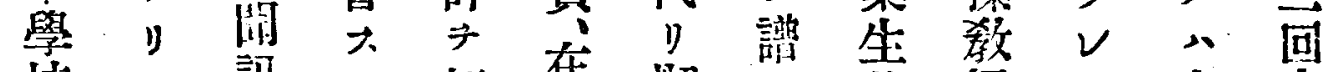

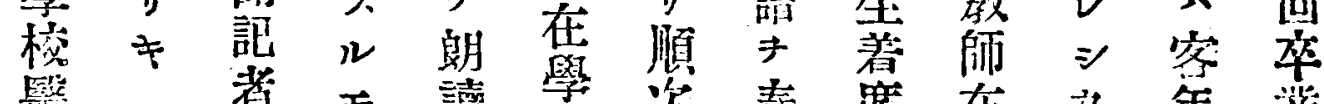

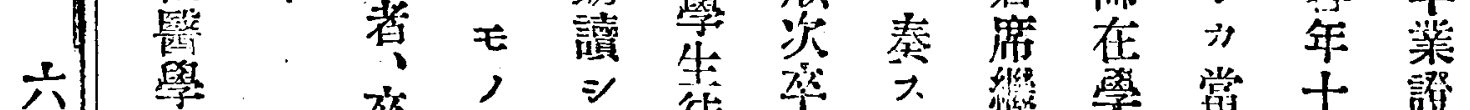

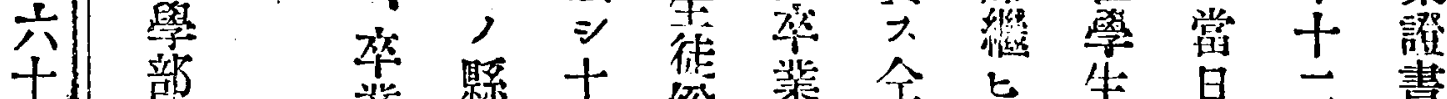

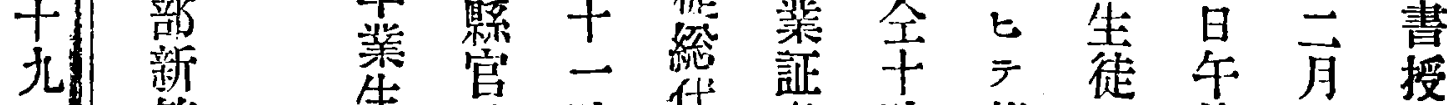

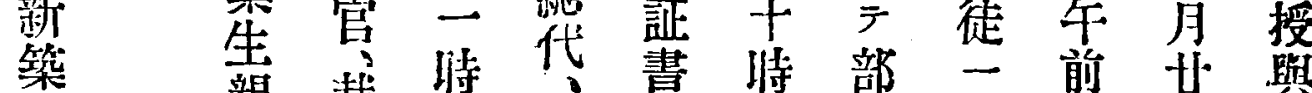
建 親 裁 恃 等 $\Rightarrow$ 部 部

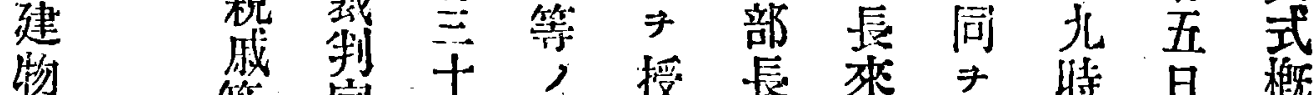
肳等 官一管授 長 来 7 恃 日 概

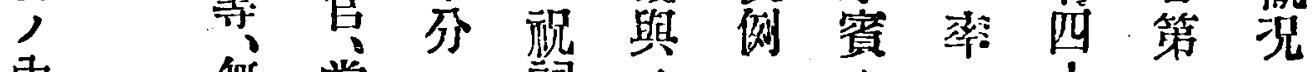

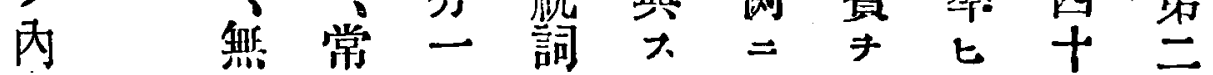

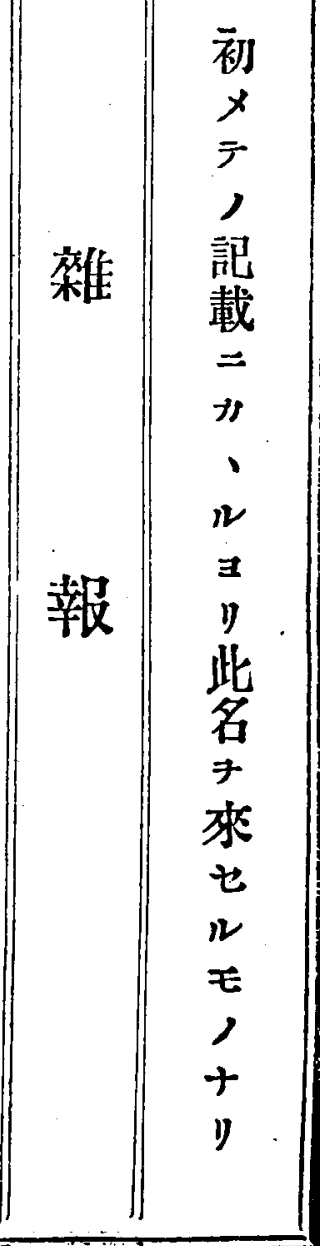


高高藤 宇三河荒 晴 難 䈏 第 橋 畑田野宮合木木波村畐第 武。荒野宫佐茟龜金卒第 三連次洁次太之䆝次業回 郎 太郎 武一郎 郎 進太郎 面 業 士岩平香平阅士岡平洞平爱平岡平島平岡平島 名 書 族手民川民山族山民山民废民山民根此山民根左 授

近矢西島三赤野沛陶淞如式

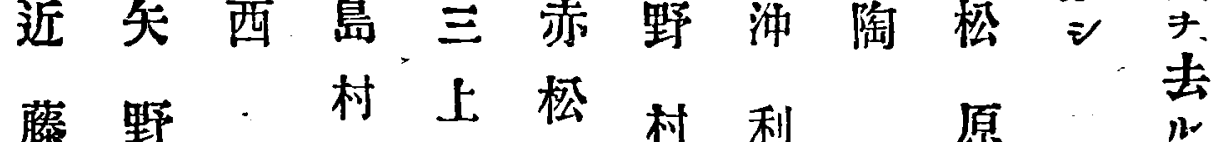


平太重，郎 郎 郎 吉 太器 三 平岡平岡平和平冏平岡平岡平洞士岡平香平香 民山民山民歌民山民山民山民山族山民川民川 山 + 㝵 H 五 日 舉

\section{生 本} 䣽 舘 扣 及 所 $t$ 第 病 各 第 院 敎 高 如埕 等 挐 蒝 中 嶨 桃 學 梖 校百公 上 秝 學 旨品

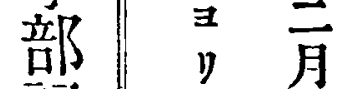
記 起 廿 事

I

大 日

ル 竣

$\Rightarrow$ I

₹ 其 他

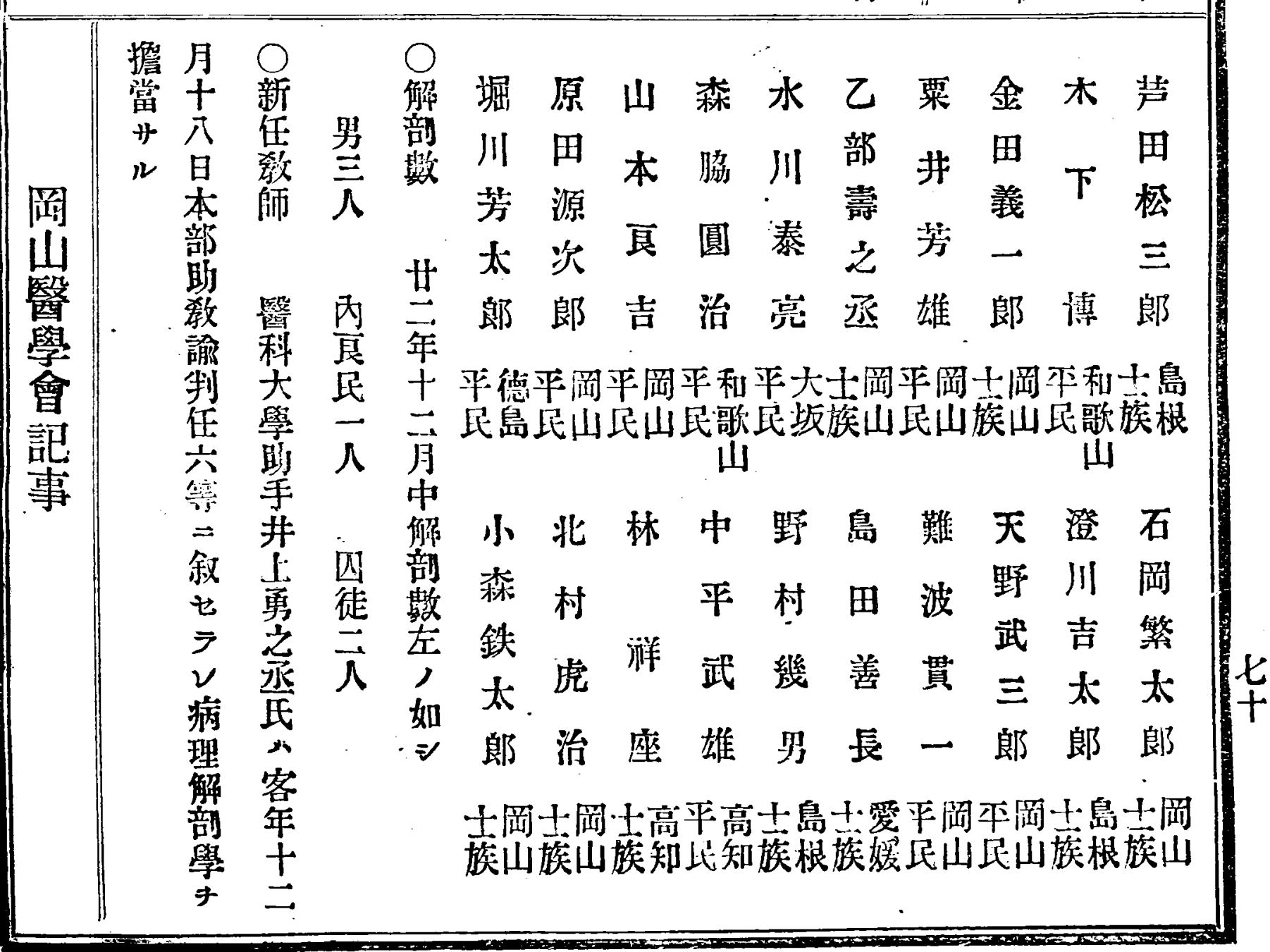

